
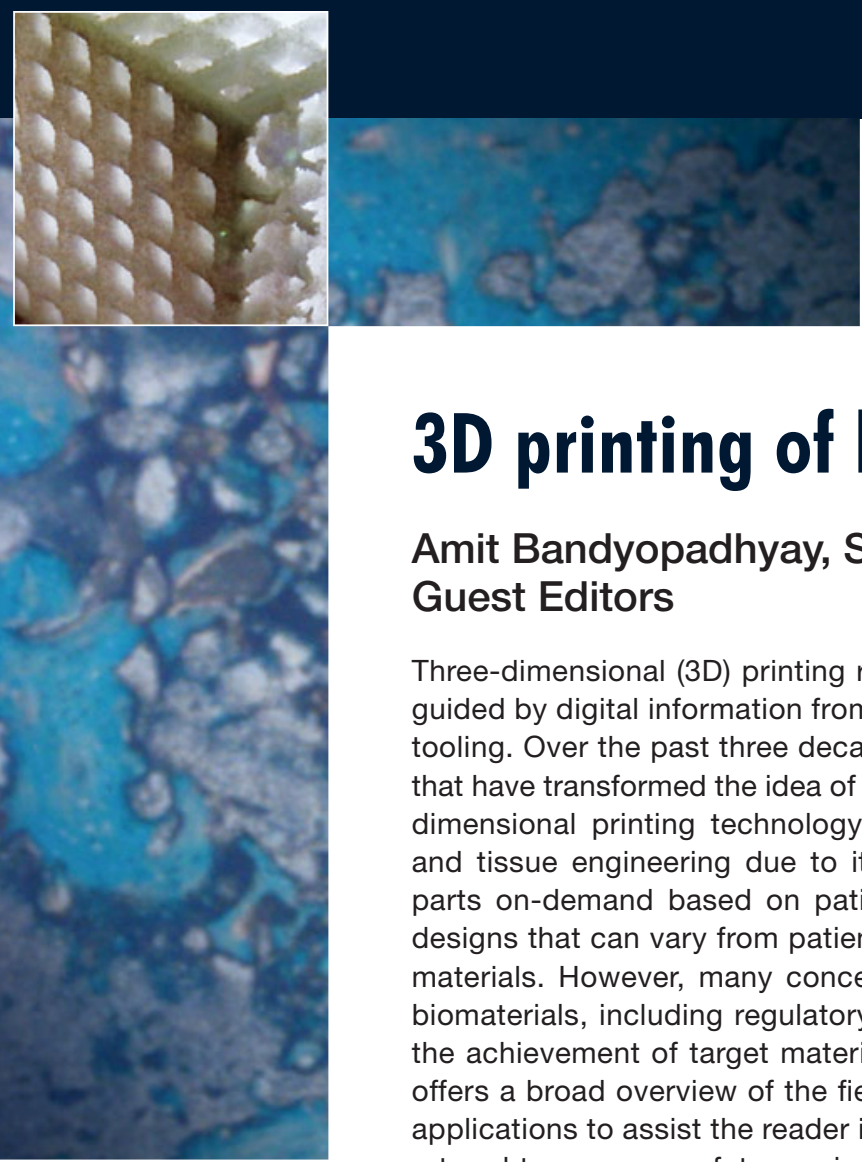

\title{
3D printing of biomaterials
}

\author{
Amit Bandyopadhyay, Susmita Bose, and Suman Das, \\ Guest Editors
}

\begin{abstract}
Three-dimensional (3D) printing represents the direct fabrication of parts layer-by-layer, guided by digital information from a computer-aided design file without any part-specific tooling. Over the past three decades, a variety of 3D printing technologies have evolved that have transformed the idea of direct printing of parts for numerous applications. Threedimensional printing technology offers significant advantages for biomedical devices and tissue engineering due to its ability to manufacture low-volume or one-of-a-kind parts on-demand based on patient-specific needs, at no additional cost for different designs that can vary from patient to patient, while also offering flexibility in the starting materials. However, many concerns remain for widespread applications of 3D-printed biomaterials, including regulatory issues, a sterile environment for part fabrication, and the achievement of target material properties with the desired architecture. This article offers a broad overview of the field of 3D-printed biomaterials along with a few specific applications to assist the reader in obtaining an understanding of the current state of the art and to encourage future scientific and technical contributions toward expanding the frontiers of 3D-printed biomaterials.
\end{abstract}

\section{Introduction}

Three-dimensional (3D) printing, also known variously as additive manufacturing (AM), layered manufacturing, rapid prototyping (RP), or solid freeform fabrication, represents the direct fabrication of parts layer-by-layer, guided by digital information from a computer-aided design (CAD) file without any part-specific tooling. In 3D printing, CAD models of parts to be manufactured are first sliced in a virtual environment to create a stack of two-dimensional (2D) slices. A 3D printing machine then builds the parts one layer at a time based on the 2D slice information, stacking and joining successive layers to make the final 3D object. Just as the internet has given us the ability to access information and connect with people from different parts of the world, CAD has provided us the ability to create, modify, and, if needed, critique, designs in a virtual world. With the advent of 3D printing, such virtual designs can now be rendered into physical 3D objects that can serve as prototypes or be directly used as functional parts for a variety of applications.

The origins of contemporary 3D printing can be traced back to the 1980s when Hull invented stereolithography (SLA), the first $3 \mathrm{D}$ printing technology. ${ }^{1}$ SLA is a process in which an ultraviolet (UV) laser light source is focused onto the surface of a UV-curable liquid monomer bath and scanned in patterns representing slice cross-sections. The scanned monomers undergo photo-induced cross-linking and harden to form the desired 2D cross-sections, while the uncured monomers remain in the bath. Hull was also the first to find a way to allow a CAD file to communicate with the RP system in order to build computer-modeled parts. Hull's patent was approved in 1986, making it the first patent for a 3D printer. The company 3D Systems, founded by Hull, focused on commercializing SLA systems, which were the first commercial 3D printers. ${ }^{2}$

Fast forward to 2014, when the US National Aeronautics and Space Administration launched the first 3D printing machine to the International Space Station to directly build parts in space under zero gravity. ${ }^{3}$ This is also the year when researchers from Oak Ridge National Laboratory built a complete car body using a 3D printing technique known as big area additive manufacturing and partnered with Local Motors to commission and drive a functional car at the International Manufacturing Technology Show. ${ }^{4}$ Threedimensional printing-based agile manufacturing technologies 
are promoting on-demand production with traditional as well as innovative designs that are difficult, if not impossible, to make through conventional manufacturing (CM) approaches. Three-dimensional printing technologies are also making a significant impact in biomedical research - from device designs to tissue engineering (TE) to bioprinting and drug delivery, which is the focus of this issue of MRS Bulletin.

\section{Brief history of 3D printing}

Several 3D printing technologies were conceived and developed around the time of the emergence of SLA. Deckard invented selective laser sintering (SLS) while a graduate student in Beaman's group at the University of Texas at Austin. ${ }^{5}$ SLS uses powder materials spread on a build plate where a laser selectively sinters the powder in certain areas based on the CAD file. ${ }^{3}$ A similar powder bed-based concept formed the basis of another technology, 3D printing, at the Massachusetts Institute of Technology by Sachs' group. Inkjet printing was combined with a powder bed, where a binder was printed onto each successive layer of swept powder based on CAD slice information. Using this approach, complex shaped metal, polymer, and ceramic parts could be printed. However, post-processing or sintering steps were often required to enhance the final strength of the parts. ${ }^{6}$ Scott and Lisa Crump developed another 3D printing technology called fused deposition modeling (FDM). FDM involves heating a thermoplastic filament to a semi-liquid state, which is then extruded and deposited through a nozzle onto a substrate to build parts layer-by-layer based on the CAD file information. ${ }^{7,8}$ Additionally, Sanders released the first $3 \mathrm{D}$ printer based on inkjet printing of thermoplastic polymers. ${ }^{9}$ Parts with fine features could be made easily using this approach. These are some of the notable early-stage 3D printing technologies that were primarily focused on RP for design verification and visualization.

Over the past 15 years, a variety of new technologies have evolved that have transformed the idea of RP to AM, where parts produced by a 3D printer can be directly used for a variety of applications. In the case of metallic materials, laser-based or electron beam-based technologies with or without a powder bed have truly revolutionized industrial applications of these printers. For biomedical applications, novel fabrication approaches based on the 3D-Bioplotter or direct ink writing, laser-assisted bioprinting, and robotic-assisted printing are all in use for different applications. Table I offers a brief summary of some of these technologies that are relevant for biomaterials and their applications toward TE. ${ }^{10-23}$ Other technologies related to metallic printing are covered throughout this issue.

An American Society for Testing and Materials (ASTM) International committee dedicated to the specification of standards for AM was formed in 2009. ${ }^{24}$ This committee, known as ASTM F42, created a categorization of all 3D printing technologies into seven major groups. Table II shows the major categories along with the well-known 3D printing technologies that fit within each category.

\section{Advantages of 3D printing toward biomedical devices}

Three-dimensional printing technology offers significant advantages for biomedical devices and TE due to the ability to manufacture low-volume or one-of-a-kind parts on-demand based on patient-specific needs. For example, surgical implants are currently manufactured by making a near-net-shape part via forging, casting, or machining operations, followed by specialized surface finishing or treatments for the desired surface, mechanical properties, and aesthetic effects, as shown in Figure 1. These operations require expensive tooling; therefore, patient-specific or one-of-a-kind implants are costly and are rarely used. Other challenges such as difficulty in machining of titanium alloys due to high strength, low modulus of elasticity, and low thermal conductivity compared to steel makes it more expensive to manufacture patient-specific implants from these materials. ${ }^{25}$ Finally, CM technologies can be energy intensive, producing significant amounts of materials waste, and are not capable of easily producing implants with functional gradation.

Three-dimensional printing or AM represents a new option for the production of a variety of biomedical devices such as orthopedic implants. Although AM may require final machining, the AM-based approach allows significant flexibility toward manufacturing customized, low-volume, complex implants. Figure 1 compares CM of implants with AM. AM provides geometrical freedom to designers without manufacturing constraints, leading to novel light-weight designs and potentially reduced part counts for medical implants. Specifically for medical implants, AM allows for customized complex shaped functional implants and demand-based manufacturing - which can offer a significant reduction in cost and inventory. Since AM does not require any partspecific tooling, cost per part remains constant for AM. However, for CM, there is always a fixed cost for tooling and dies, and therefore, cost per part decreases as the volume of parts increases until it reaches a minimum. Such cost analysis forms the basis and rationale for the use of $3 \mathrm{D}$ printing or AM for biomedical devices.

Despite some noteworthy successes, the construction of human tissue or entire organs with $3 \mathrm{D}$ printing or AM continues to present significant challenges. ${ }^{26-29}$ From plastic surgery to cancer treatment and from treatment of birth defects to prosthetics for amputees - all areas of medicine are seeking breakthroughs enabled by $3 \mathrm{D}$ printing to enhance quality of life or to help patients live longer.

We present two examples that illustrate future possibilities. Complex craniofacial titanium implants from computed tomography images of a fractured skull, shown in Figure 2, can be fabricated directly using a laser-based AM technology, Laser Engineered Net Shaping. Another example, shown in Figure 3, TE scaffolds for bone regeneration can be produced through SLS of poly(caprolactone), a biocompatible and bioresorbable polymer, and poly(caprolactone)hydroxyapatite composites. ${ }^{30,31}$ Furthermore, the scaffolds can be produced with a priori designed mechanical properties 
Table I. Three-dimensional printing technologies and their applications in biomaterials.

\begin{tabular}{|c|c|c|c|c|}
\hline Technique & Process Details & $\begin{array}{c}\text { Processed Materials for Tissue } \\
\text { Engineering }\end{array}$ & Advantages and Disadvantages & References \\
\hline \multirow[t]{2}{*}{$\begin{array}{l}\text { 3D plotting/direct } \\
\text { ink writing }\end{array}$} & \multirow[t]{2}{*}{$\begin{array}{l}\text { Extrusion-based layer-by-layer } \\
\text { deposition }\end{array}$} & \multirow{2}{*}{$\begin{array}{l}\text { A variety of polymers and } \\
\text { ceramics have already been } \\
\text { used, including polycaprolactone } \\
\text { (PCL), hydroxyapatite (HA), } \\
\text { bioactive glasses, polylactic acid } \\
\text { (PLA)/polyethylene glycol (PEG), } \\
\text { and poly(hydroxymethylglycolide- } \\
\text { co- } \varepsilon \text {-caprolactone). }\end{array}$} & $\begin{array}{l}\text { Advantage } \\
\text { - Easy to incorporate both drug } \\
\text { and biomolecules (proteins and } \\
\text { living cells) }\end{array}$ & \multirow[t]{2}{*}{$10-13$} \\
\hline & & & $\begin{array}{l}\text { Disadvantages } \\
\text { - Post-processing may be needed } \\
\text { for some materials. } \\
\text { - Process works well within a certain } \\
\text { range of viscosity. }\end{array}$ & \\
\hline \multirow[t]{2}{*}{$\begin{array}{l}\text { Laser-assisted } \\
\text { bioprinting }\end{array}$} & \multirow{2}{*}{$\begin{array}{l}\text { Coating the desired material } \\
\text { on transparent quartz disk } \\
\text { (ribbon). The deposition is } \\
\text { controlled by laser pulse } \\
\text { energy, and resolution is } \\
\text { controlled by distance } \\
\text { between ribbon/substrate, } \\
\text { spot size, and stage } \\
\text { movement. }\end{array}$} & \multirow{2}{*}{$\begin{array}{l}\text { A variety of materials, including } \mathrm{HA} \text {, } \\
\text { zirconia, HA/MG63 (osteoblast- } \\
\text { like cell), human osteoprogenitor } \\
\text { cell (i.e., a cell that has the } \\
\text { potential to transform into one } \\
\text { that forms bone), and human } \\
\text { umbilical vein endothelial cell }\end{array}$} & $\begin{array}{l}\frac{\text { Advantage }}{\text { - Ambient and mild condition is }} \\
\text { suitable for organic and inorganic } \\
\text { materials and cells. }\end{array}$ & \multirow[t]{2}{*}{14,15} \\
\hline & & & $\begin{array}{l}\text { Disadvantage } \\
\text { - Homogeneous ribbons are needed. }\end{array}$ & \\
\hline \multirow[t]{2}{*}{$\begin{array}{l}\text { Selective laser } \\
\text { sintering }\end{array}$} & \multirow[t]{2}{*}{$\begin{array}{l}\text { A powder bed-based process } \\
\text { that partially or completely } \\
\text { sinters layer-by-layer using } \\
\text { a laser-based heat source. }\end{array}$} & \multirow[t]{2}{*}{$\begin{array}{l}\text { A large variety of polymers, } \\
\text { metals, and ceramic materials } \\
\text { have been used with this } \\
\text { technique, including PCL, HA, } \\
\text { PLLA, tricalcium phosphate, } \\
\text { and poly(3-hydroxybutyrate). }\end{array}$} & $\begin{array}{l}\text { Advantages } \\
\text { - Powder bed is used as support, } \\
\text { therefore no need for secondary } \\
\text { support structures. } \\
\text { - Can be used for a variety of } \\
\text { materials }\end{array}$ & \multirow[t]{2}{*}{16,17} \\
\hline & & & $\begin{array}{l}\text { Disadvantage } \\
\text { - Feature resolution depends on } \\
\text { laser-beam diameter. }\end{array}$ & \\
\hline \multirow[t]{2}{*}{ Stereolithography } & \multirow[t]{2}{*}{$\begin{array}{l}\text { Layer-by-layer fabrication by } \\
\text { exposure to photopolymer } \\
\text { liquid. Polymer solidifying } \\
\text { at the focal point, and } \\
\text { un-exposed polymer } \\
\text { remains liquid. }\end{array}$} & \multirow[t]{2}{*}{$\begin{array}{l}\text { A large variety of photo-curable } \\
\text { polymers }\end{array}$} & $\begin{array}{l}\text { Advantage } \\
\text { - Simple and complex designs can } \\
\text { be manufactured. Growth factors, } \\
\text { proteins, and cells can also be } \\
\text { done. }\end{array}$ & \multirow[t]{2}{*}{18,19} \\
\hline & & & $\frac{\text { Disadvantage }}{\text { Only applicable for photopolymers }}$ & \\
\hline \multirow[t]{2}{*}{$\begin{array}{l}\text { Fused deposition } \\
\text { modeling }\end{array}$} & \multirow{2}{*}{$\begin{array}{l}\text { Strands of thermoplastic } \\
\text { polymers or polymer/ceramic } \\
\text { composites extruded through } \\
\text { a tip and deposited layer-by- } \\
\text { layer }\end{array}$} & \multirow[t]{2}{*}{$\begin{array}{l}\text { Structural and biopolymers, } \\
\text { ceramic-polymer, or metal- } \\
\text { polymer composites }\end{array}$} & $\begin{array}{l}\text { Advantage } \\
\text { - Easy to use and can be used with } \\
\text { a large variety of materials }\end{array}$ & \multirow[t]{2}{*}{$20-22$} \\
\hline & & & $\begin{array}{l}\text { Disadvantage } \\
\text { - Material restriction related to } \\
\text { thermoplastic polymers }\end{array}$ & \\
\hline \multirow[t]{2}{*}{$\begin{array}{l}\text { Robotic assisted } \\
\text { deposition/ } \\
\text { robocasting }\end{array}$} & \multirow{2}{*}{$\begin{array}{l}\text { Direct writing of high solids } \\
\text { loaded slurry. Good for } \\
\text { a variety of ceramics } \\
\text { and ceramic-polymer } \\
\text { composites. }\end{array}$} & \multirow[t]{2}{*}{$\begin{array}{l}\text { HA/PLA, HA/PCL, and bioactive } \\
\text { glass }(6 \mathrm{P} 53 \mathrm{~B}) / \mathrm{PCL}\end{array}$} & $\begin{array}{l}\underline{\text { Advantage }} \\
\text { - Good for ceramics }\end{array}$ & \multirow[t]{2}{*}{23} \\
\hline & & & $\begin{array}{l}\text { Disadvantage } \\
\text { - May not be useful for different } \\
\text { materials }\end{array}$ & \\
\hline
\end{tabular}

to match the desired mechanical performance of the target bone tissue.

It is envisioned that application of $3 \mathrm{D}$ printing will revolutionize the field of biomedical devices and TE due to its inherent flexibility in manufacturing complex parts using various materials. However, many challenges still remain, due to a lack of different materials for use in any printer and the inability to manufacture multicomponent structures using commercial printers. 
Table II. Three-dimensional printing techniques and respective vendors.

\begin{tabular}{|c|c|}
\hline Category & Commercial 3D Printing Technologies and Vendors \\
\hline Vat photopolymerization & $\begin{array}{l}\text { - Stereolithography from 3D Systems } \\
\text { - Bioplotters from Envisiontec } \\
\text { - Large Area Maskless Photopolymerization from DDM Systems } \\
\text { - Lithoz Lithography-Based Ceramic Manufacturing }\end{array}$ \\
\hline Material extrusion & - Fused Deposition Modeling from Stratasys \\
\hline Powder bed fusion & $\begin{array}{l}\text { - Selective Laser Sintering from 3D Systems } \\
\text { - Electron Beam Melting from Arcam AB } \\
\text { - Direct Metal Laser Sintering from EOS } \\
\text { - Selective Laser Melting from SLM Solutions }\end{array}$ \\
\hline Directed energy deposition & $\begin{array}{l}\text { - Laser Engineered Net Shaping from Optomec Inc. } \\
\text { - Direct Metal Deposition from DM3D } \\
\text { - Electron Beam Welding from Sciaky Inc. }\end{array}$ \\
\hline Material jetting & $\begin{array}{l}\text { - Objet from Stratasys } \\
\text { - Solidscape 3D Printers from Solidscape } \\
\text { - Multi-jet Fusion Technology from HP }\end{array}$ \\
\hline Binder jetting & $\begin{array}{l}\text { - ZCorp } \\
\text { - ExOne } \\
\text { - Voxeljet }\end{array}$ \\
\hline Sheet lamination & MCor Technologies \\
\hline
\end{tabular}

and documented under diverse conditions both in vitro and in vivo.

The challenges increase when the implants are endowed with intentionally designed or manufacturing-induced porous architectures. The effective mechanical properties and failure modes of such porous architectures need to be well understood and integrated into implant design procedures to avoid undesirable implant failure outcomes. Computational design techniques validated with experimentally measured property data need to be integrated into implant design procedures. Additional challenges lie in the ability of $3 \mathrm{D}$ printing technologies to accurately produce desired porous architectures meeting design intent. Often, the length scales associated with the designed porous architectures (ranging from tens to hundreds of microns) are beyond the resolution capability of the 3D printing technology in use.

Finally, surface finish or surface roughness can be a critical requirement as well. The inherent stair-stepped surface finish from layer-by-layer fabrication or other material consolidation-induced surface roughness artifacts prevalent in $3 \mathrm{D}$ print-

\section{Current challenges in 3D printing of biomaterials Achieving target material properties and desired architectures}

By virtue of layer-by-layer additive fabrication, it is claimed that 3D printing provides "complexity for free," allowing the physical realization of complex 3D structures endowed with complex internal and external architectures. However, every layer and every interface between adjacent layers provides the opportunity for the introduction of defects during 3D printing that can lead to failure of the part under the intended application conditions.

Some of the key challenges associated with 3D printing of biomedical implants lie in achieving target mechanical properties, durability, and designed architectures to satisfy both mechanical and functional requirements. This is especially important in load-bearing implants, where mechanical performance and fatigue are critical. Three-dimensional printing technologies are being used to produce permanent implants in metals, polymers, and ceramics. The capabilities of these technologies in processing feedstock materials such as titanium, poly(ether ether ketone), and hydroxyapatite need to be well-characterized ing are often beneficial for cell anchoring, proliferation, and integration, but in other cases, they can be highly detrimental due to the inducement of foreign body reactions or due to the release of particles into regions surrounding the implant. Thus, careful attention has to be paid to understanding surface finish and surface texture requirements as well as choosing appropriate post-processing procedures to attain final desired surfaces in biomaterials fabricated by $3 \mathrm{D}$ printing.

\section{Clean and sterile manufacturing environments}

Three-dimensional-printed biomaterials are being produced with the intention of use in implants or in laboratory scale

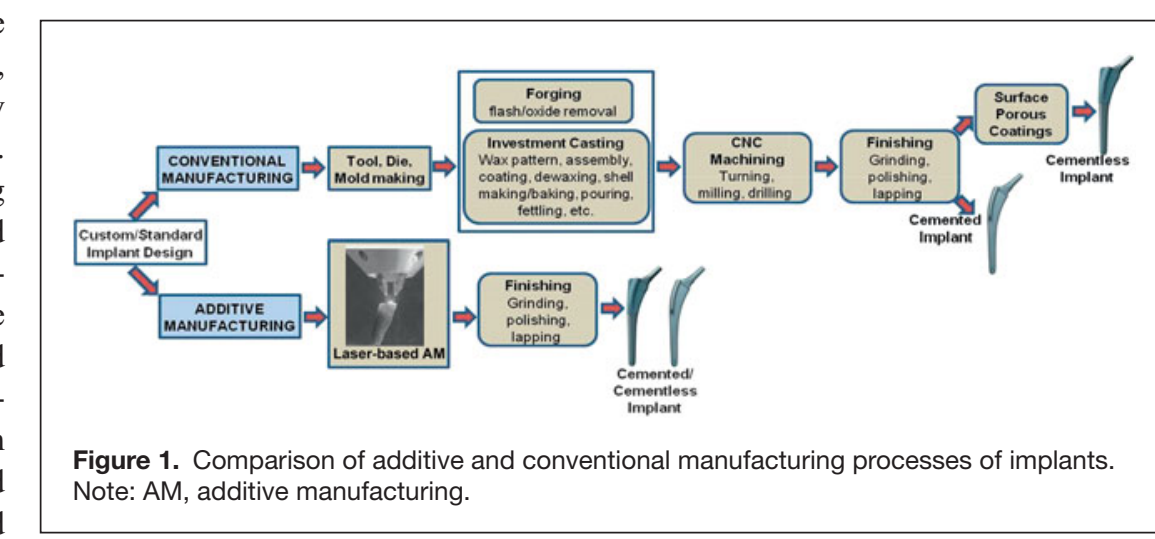




\section{D PRINTING OF BIOMATERIALS}

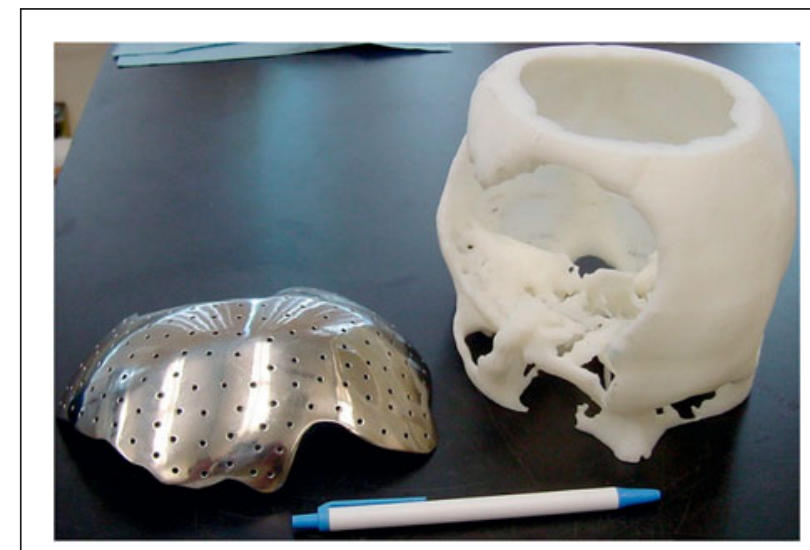

Figure 2. Laser Engineered Net Shaping processed craniofacial Ti implant (left) and fused deposition modeling processed polymer prototype of the skull with large defect (right).

studies in bioengineering. In either case, careful attention needs to be paid to the conditions under which the feedstock material is produced, supplied, processed, post-processed, and handled. The scale-up of 3D printing technologies for biomaterials will require careful design of clean manufacturing environments both inside and outside the $3 \mathrm{D}$ printing platforms to ensure the avoidance of material contamination and related possible infections. Thus, the design of 3D printing equipment for biomaterials needs to ensure that equipment subsystems can meet the requirements for contamination control, perhaps similar to or even more stringent than those applied in the medical device industry. Furthermore, clean manufacturing environments will need to be designed from the ground up for scale-up manufacturing of 3D-printed biomaterials. New sterilization, packaging, and shipping procedures for 3D-printed biomaterials need to be developed to ensure product integrity at the point of use.

\section{Concerns related to regulatory issues}

Regulatory issues are specific to a particular country and should be checked for that particular region first. In the United States, medical devices are classified under three categories based on the risk to the patient: Class I, Class II, and Class III. Class I devices are typically the lowest risk (e.g., a tongue depressor). If there is a predicate device, then many devices are classified under Class II, where the new device is substantially equivalent to the previous device, which has already been cleared by the US Food and Drug Administration. Regulatory paths for the Class III or highrisk devices are quite challenging as well as time-consuming. In most cases, regulation follows technology development, and therefore, many times there is a lag in appropriate regulations for certain types of devices.
This is the case for 3D printing and its applications to human health. Though the technology for patient-specific implants is available, no clear regulatory path is established toward immediate utilization of this technology. This is also because the risk associated with the use of this technology is yet to be fully understood and evaluated. A TE graft with tailored porosity and chemistry can be fabricated in hours; however, the scientific factors that need to be verified to confirm that this will perform the same way as before are still evolving. Moreover, the advent of different 3D printing technologies is also making this evaluation more complex. Finally, the needs of specific patients are different. A clear understanding of the biomechanical and biological issues for different parts will eventually help develop regulatory pathways for diverse clinical applications of 3D-printed parts. A logical approach will establish regulatory paths for low-risk devices, such as specialty surgical tools, and then slowly move toward the high-risk devices such as patient-matched implants. It is envisioned that such trends will follow in the coming years in the United States as well as other parts of the world.

\section{Material-specific machines}

Unlike CM processes such as forging or investment casting, many 3D printing processes are different in terms of the materials that can be used and the delivery of materials. For example, a polymer-based 3D printing process will not work for metals or ceramics and vice versa. This makes process optimization very important for different materials that will be used with a specific printer. The user must know what material will be used and what kind of resolution is needed before selecting a 3D printer. This limitation is the main reason why different companies have multiple $3 \mathrm{D}$ printers for a variety of applications.

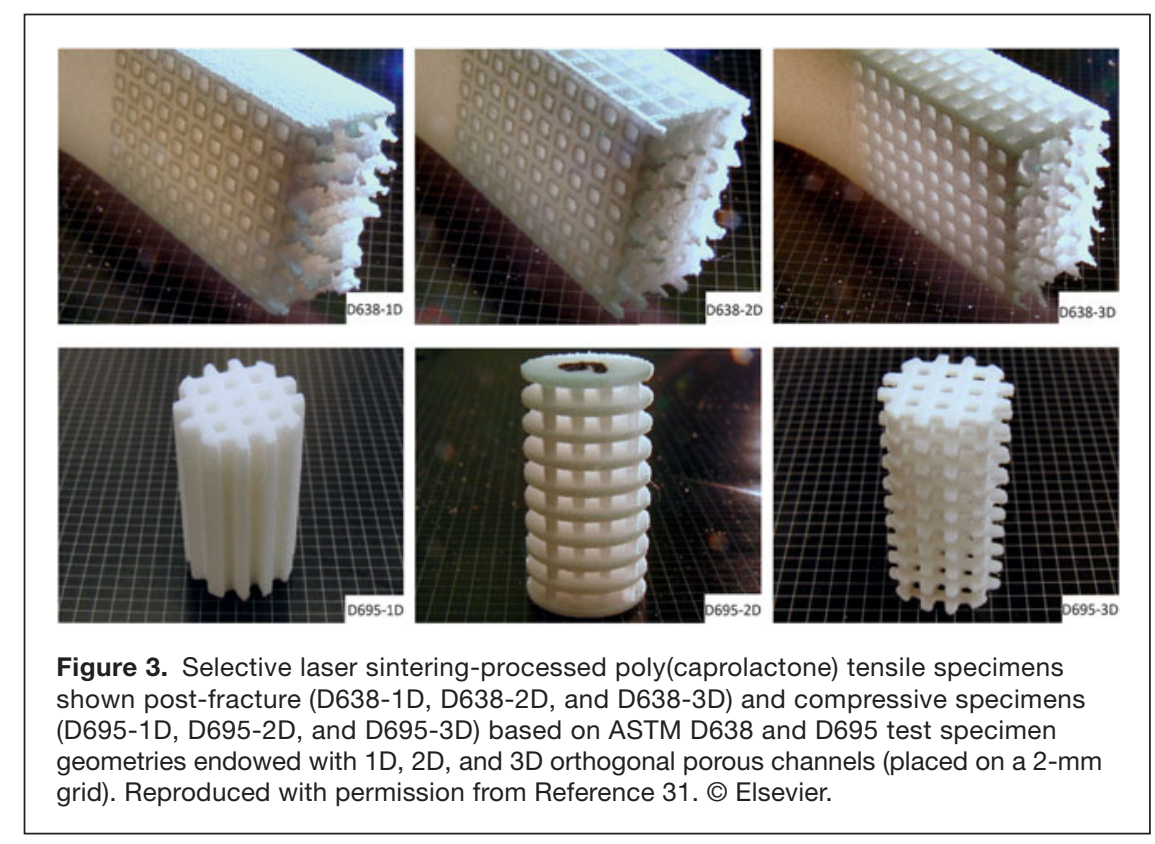




\title{
Bioprinting, biofabrication, biomanufacturing? The need for definitions and norms in additive manufacturing in the biomedical sciences
}

\author{
Dietmar W. Hutmacher
}

The additive manufacturing (AM) industry has undergone tremendous growth in its history, which started in 1987 with the first commercialization of stereolithography. With a steady increase in the number of annual Patent Cooperation Treaty patents, the AM industry is poised for significant technological innovations. Further proof of this is seen in the recent exponential increase in three-dimensional (3D) printer and software companies and their range of products, with several in the low-cost market. This is creating opportunities for adoption of this technology by the consumer in a way that has never been economically feasible in the past.

An analysis of several leading reviews as well as industry reports suggest that the so-called "MedTech sector" could be one of the greatest beneficiaries of the application of AM technology, with clear patient, healthcare system, biotechnology, and medical device industry benefits. According to research reports from Transparency Market Research ${ }^{1}$ and Roots Analysis, ${ }^{2}$ the global market for 3D printing for medical applications was valued at $\$ 360$ million in 2012 and is expected to grow at a compounded annual growth rate of 15.4 percent from 2013 to 2019 , to reach $\$ 970$ million by 2019 . AM has already been embraced in many surgical specialties, especially orthopedics and neurosurgery. The technology has allowed physicians to create custom-fit medical devices for their patients, and examples of how the technology has directly affected patients include custom orthotic insoles, personalized prosthetics, surgical guides, and one-off implants. ${ }^{3}$ The application of AM represents one of the most rapidly advancing areas of biomedical sciences in which engineers, scientists, and clinicians are contributing to the future of human health care and, more specifically, to areas of medical devices, tissue engineering (TE), regenerative medicine (RM), and in vitro disease model development. ${ }^{4}$

There is an increasing trend of single groups or larger research consortia inventing their own definitions and terminology, which often makes it difficult to find and compare the results of the published work. Therefore, to move the field constructively forward, it is a condition sine qua non to clarify terms such as biomanufacturing, biofabrication, bioprinting, and cell printing, which are often used interchangeably in the literature.

$\mathrm{AM}$ has become a game-changing technology in the TE and RM fields since the first published application of $3 \mathrm{D}$ printing of scaffolds in $1996 .^{5,6}$ In contrast to the medical device industry, the TE and RM communities have not adopted AM terminology and have instead invented a new set of terms, such as cell printing, bioprinting, biomanufacturing, and biofabrication. These terms are again used interchangeably. They are based on the principles of AM, and therefore should be defined under American Society for Testing and Materials (ASTM) International and the International Organization for Standardization (ISO) norms.

In this fast-growing, ever-changing industry, terminology evolves rapidly, so the academic and industry AM communities began to work with ASTM International in 2009. Within the working group, a consensus was reached in 2012, and since then, ASTM defined AM as:

"Additive manufacturing is the official industry standard term for all applications of technologies which use a process of joining materials to make objects from in silico 3D model data sets, usually layer upon layer, as opposed to subtractive manufacturing methodologies. Synonyms used in the literature are additive fabrication, additive processes, additive techniques, additive layer manufacturing, layer manufacturing, and freeform fabrication, yet with authoritarianism of the working group, the ASTM F2792 has unified the field in respect to terminology."

The ASTM International F42 Committee on Additive Manufacturing Technologies is playing an instrumental role in the advancement of AM. The committee, with a current membership of approximately 215, has four technical subcommittees; all standards developed by F42 are published in the Annual Book of ASTM Standards. As of December 2014, ASTM had published 10 industry standards, with many others in development.

Five new standards are focused on AM terminology, testing, data reporting for test specimens, Ti-6Al-4V titanium alloys, and the ASTM Additive Manufacturing File Format as an alternative to STL, which is the file format of the stereolithography computeraided design software designed by 3D Systems. These standards are important because they will help organizations qualify AM processes and materials faster and less expensively. Most businesses do not fully mature without well-developed industry standards, so the development of AM standards is an important trend, and the biomedical research community working on translational research projects should learn and adapt to such commercially driven governance.

It would be beneficial to the biomedical community, and specifically the TE and RM field, that a new ASTM/ISO norm is developed or a new sub-norm is defined as "additive biomanufacturing" under ASTM F2792 in order to define the terms biofabrication and bioprinting.

\section{References}

1. Transparency Market Research, http://www.transparencymarketresearch. com/3d-printing-industry.html.

2. Roots Analysis, http://www.marketresearch.com/Roots-Analysis-PvtLtd-v3981/3D-Bioprinting-8071110/

3. F.A. Probst, D.W. Hutmacher, D.F. Müller, H.G. Machens, J.T. Schantz, Handchir Mikrochir Plast Chir. 42 (6), 369 (2010).

4. P.F. Costa, C. Vaquette, J. Baldwin, M. Chhaya, M.E. Gomes, R.L. Reis, C. Theodoropoulos, D.W. Hutmacher, Biofabrication 6 (3), 035006 (2014).

5. D.W. Hutmacher, Biomaterials 21 (24), 2529 (2000).

6. F.P.W. Melchels, M.A.N. Domingos, T.J. Klein, J. Malda, P.J. Bartolo, D.W. Hutmacher, Prog. Polym. Sci. 37 (8), 1079 (2012).

7. ASTM F2792 ASTM F2792-12a, "Standard Terminology for Additive Manufacturing Technologies" (ASTM International, West Conshohocken, PA, 2012), www.astm.org. 


\section{In this issue}

The articles in this issue of MRS Bulletin discuss 3D printing of different types of biomaterials that are of significant interest, from load-bearing implants to TE to bioprinting. Childers et al. discuss 3D-printed resorbable polymeric scaffolds, primarily made of poly(propylene fumarate), for TE applications. Different 3D printing approaches to make these scaffolds along with the influence of porosity and degradation kinetics on clinical application of these scaffolds are discussed. The article by Vorndran et al. focuses on 3D printing of different ceramics, their advantages and disadvantages, and their in vitro and in vivo performance in TE and drug delivery. Regis et al. present 3D printing of porous metallic loadbearing implants, implant mechanical properties, biological properties, and clinical performance to show some of the inherent advantages of AM. The article by $\mathrm{Li}$ et al. focuses on bioprinting involving various $3 \mathrm{D}$ printing approaches aimed at TE, growth factor delivery, cell delivery, and regeneration of various organs. Finally, the sidebar article by Hutmacher discusses the need for definitions and norms applied to application of AM toward biomedical sciences. This issue offers a broad overview of the field of 3D-printed biomaterials along with a few specific applications that can assist the reader in obtaining an understanding of the current state of the art and to enable future scientific and technical contributions toward expanding the frontiers of 3D-printed biomaterials across a range of length scales.

\section{Future trends}

Three-dimensional printing of multi-material structures is one of the most promising future trends. Different materials at different locations in a structure can offer properties that cannot be achieved using monolithic structures. These materials can only be bonded to each other or alloyed during the part building, allowing for compositional variations in the part. For 3D-printed biomaterials, a simple example can help us understand the power of multi-material 3D printing. For total hip prosthesis, implants are made with either Ti6A14V or CoCrMo alloys. To enhance bone-tissue integration, implants are sometimes coated with porous $\mathrm{Ti}$ or Ta metal or calcium phosphate-based ceramics. However, different processing strategies are utilized for the addition of coatings. Using multi-material 3D printing, a calcium phosphate or metal coated hip stem can be directly manufactured from the same machine that can also produce an uncoated sample in the very next run. Therefore, in addition to flexibility in design modifications, the potential of incorporating compositional variations will allow future innovations in advanced materials and structures using 3D printing.

For bioprinting, multi-material structures include cells that can be printed along with organic or inorganic materials to make a fully functional scaffold for TE. ${ }^{32}$ Such an approach is gaining considerable attention from a number of researchers, though there are many challenges that need careful attention. For example, cell viability will be key for successful bioprinting operation. Shelf-life of materials with and without

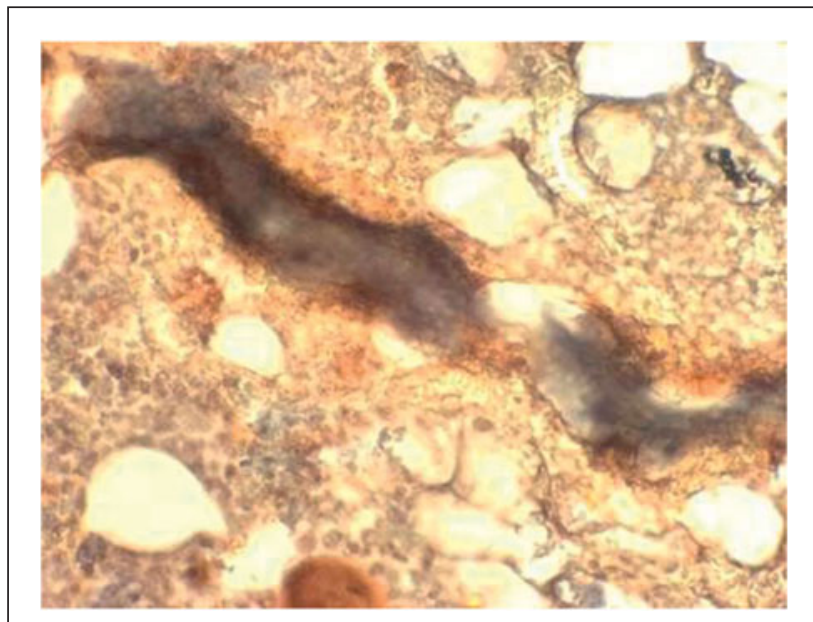

Figure 4. New blood vessel formation in 3D-printed-doped tricalcium phosphate TE scaffolds implanted in a rat distal femur model.

cells is another significant issue. Also, due to significant variation in the stiffness of the cells and materials to be deposited, careful process optimization is necessary to build scaffolds that can be used for further in vitro or in vivo analysis.

Another important criterion is vascularization or new blood vessel network formation, commonly known as angiogenesis. Figure 4 shows new blood vessel formation in 3D-printed-doped tricalcium phosphate TE scaffolds in a rat distal femur model. 3D-printed TE scaffolds should support angiogenesis for functional tissue formation to enhance healing in vivo. ${ }^{33-39}$

Finally, 3D printing combined with drug or protein delivery is becoming popular and is expected to gain more attention in the future. Drug-/protein-loaded biomaterials with a controlled delivery option can be used to treat many diseases. ${ }^{38}$ In particular, specific drug combinations that are patient-matched and unique can be loaded into a single 3D-printed drug delivery device. However, drug-material and drug-drug interactions during $3 \mathrm{D}$ printing are complex topics and will require significant process optimization before actual applications can be realized and approved for patient use.

\section{References}

1. C.W. Hull, "Apparatus for Production of Three-Dimensional Objects by Stereolithography," US Patent 4,575,330 (March 11, 1986).

2. 3D Systems Inc., http://www.3dsystems.com/.

3. Made in Space, http://www.madeinspace.us/\#section-portal.

4. Manufacturing Demonstration Facility, Oak Ridge National Laboratory, http:// web.ornl.gov/sci/manufacturing/media/news/3d-car/.

5. C.R. Deckard, "Method and Apparatus for Producing Parts by Selective Sintering," US Patent 4,863,538 (September 5, 1989).

6. E.M. Sachs, J.S. Haggerty, M.J. Cima, P.A. Williams, "Three-Dimensional Printing Techniques," US Patent 5,204,055 (1993).

7. S.S. Crump, "Apparatus and Method for Creating Three-Dimensional Objects," US Patent 5,121,329 (June 9, 1992).

8. Stratasys Ltd., http://www.stratasys.com.

9. R.C. Sanders Jr., J.L. Forsyth, K.F. Philbrook, “3-D Model Making,” US Patent 5,740,051 (April 14, 1998).

10. J.M. Sobral, S.G. Caridade, R.A. Sousa, J.F. Mano, R.L. Reis, Acta Biomater 7, 1009 (2011).

11. C. Wu, Y. Luo, G. Cuniberti, Y. Xiao, M. Gelinsky, Acta Biomater. 7, 2644 (2011). 
12. H. Seyednejad, D. Gawlitta, R.V. Kuiper, A. de Bruin, C.F. van Nostrum, T. Vermonden, W.J. Dhert, W.E. Hennink, Biomaterials 33, 4309 (2012).

13. Q. Fu, E. Saiz, A.P. Tomsia, Acta Biomater. 7, 3547 (2011).

14. A. Doraiswamy, R.J. Narayan, M.L. Harris, S.B. Qadri, R. Modi, D.B. Chrisey, J. Biomed. Mater. Res. A. 80A (3), 635 (2007).

15. B. Guillotin, A. Souquet, S. Catros, M. Duocastella, B. Pippenger, S. Bellance, R. Bareille, M. Rémy, L. Bordenave, J. Amédée, F. Guillemot, Biomaterials 31, 7250 (2010).

16. J.M. Williams, A. Adewumni, R.M. Schek, C.L. Flanagan, P.H. Krebsbach, S.E. Feinberg, S.J. Hollister, S. Das, Biomaterials 26 (23), 4817 (2005).

17. B. Duan, M. Wang, W.Y. Zhou, W.L. Cheung, Z.Y. Li, W.W. Lu, Acta Biomater. 6, 4495 (2010).

18. P.X. Lan, J.W. Lee, Y.J. Seol, D.W. Cho, J. Mater. Sci. Mater. Med. 20, 271 (2009).

19. A. Ronca, L. Ambrosio, D.W. Grijpma, Acta Biomater. 9, 5989 (2013).

20. S.J. Kalita, S. Bose, H.L. Hosick, A. Bandyopadhyay, Mater. Sci. Eng. C 23. (5) 611 (2003).

21. S. Bose, J. Darsell, L. Yang, D.K. Sarkar, H.L. Hosick, A. Bandyopadhyay, J. Mater. Sci. Mater. Med. 13, 23 (2002).

22. J. Darsell, S. Bose, H. Hosick, A. Bandyopadhyay J. Am. Ceram. Soc. 86 (7), 1076 (2003)

23. J. Russias, E. Saiz, S. Deville, K. Gryn, G. Liu, R.K. Nalla, A.P. Tomsia. J. Biomed. Mater. Res. Part A. 83A, 434 (2007)

24. ASTM International, "Standard Test Methods for Conductivity Type of Extrinsic Semiconducting Materials (Withdrawn 2003)," available online at http://www.astm.org/Standards/F42.htm.
25. M. Balazic, J. Kopac, M.J. Jackson, W. Ahmed, Int. J. Nano Biomater. 1 (1), 3 (2007).

26. M.A. Woodruffa, C. Langeb, J. Reichertc, A. Bernerd, F. Chene, P. Fratzlb, J.-T. Schantzf, D.W. Hutmachera, Mater. Today 15, 430 (2012).

27. J.C. Reichert, A. Cipitria, D.R. Epari, S. Saifzadeh, P. Krishnakanth, A. Berner, W.A. Woodruff, H. Schell, M. Mehta, M.A. Schuetz, G.N. Duda, D.W. Hutmacher, Sci. Transl. Med. 4, 141ra93 (2012).

28. F.P.W. Melchels, M.A.N. Domingos, T.J. Klein, J. Malda, P.J. Bartolo, D.W. Hutmacher, Prog. Polym. Sci. 37, 1079 (2012).

29. D.W. Hutmacher, J. Mater. Sci. Mater. Med. 24 (11), 2659 (2013).

30. S. Eshraghi, S. Das, Acta Biomater. 8 (8), 3138 (2012).

31. S. Eshraghi, S. Das, Acta Biomater. 6 (7), 2467 (2010).

32. R. Bradley, R.K. Ringeisen, P.K. Pirlo, T.B. Wu, H. Yong, S. Wei, H. Qudus, D.B. Chrisey, MRS Bull. 38 (10), 834 (2013).

33. G. Fielding, S. Bose, Acta Biomater. 9 (11), 9137 (2013)

34. S. Tarafder, W.S. Dernell, A. Bandyopadhyay, S. Bose, J. Biomed. Mater. Res. Part B (2014), doi: $10.1002 / \mathrm{jbm} . b .33239$

35. S. Tarafder, N.M. Davies, A. Bandyopadhyay, S. Bose, Biomater. Sci. 1, 1250 (2013)

36. S. Bose, M. Roy, A. Bandyopadhyay, Trends Biotechnol. 30 (10), 546 (2012).

37. S. Bose, G. Fielding, S. Tarafder, A. Bandyopadhyay, Trends Biotechnol. 31 (10), 594 (2013)

38. S. Bose, S. Tarafder, Acta Biomater. 8 (4), 1401 (2012)

39. S. Tarafder, S. Bose, ACS Appl. Mater. Interfaces 6 (13), 9955 (2014).
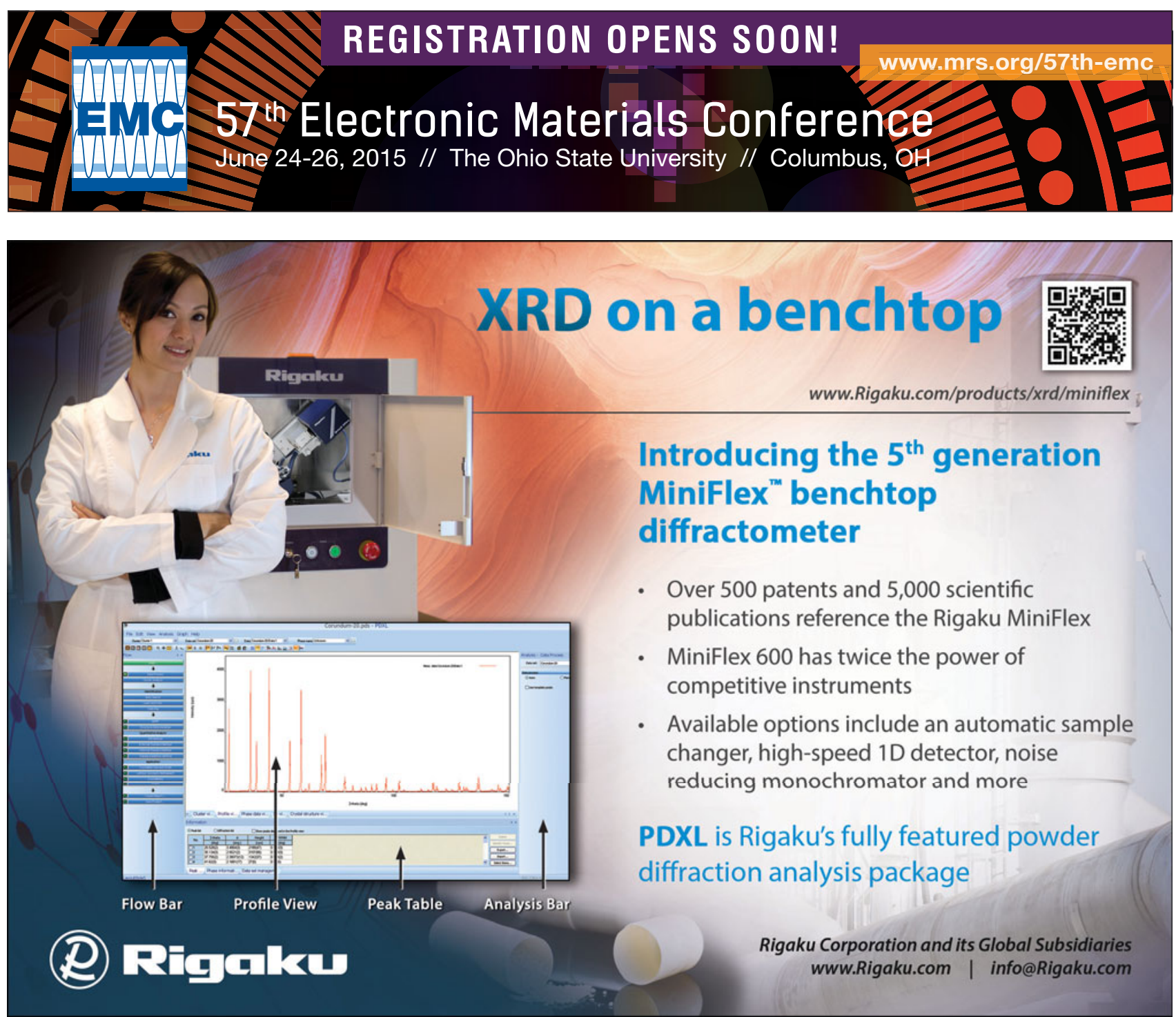